\title{
Adiestramiento del búfalo (Bubalus bubalis) como animal de trabajo
}

\author{
Training the buffalo (Bubalus bubalis) as a work animal
}

\section{Treinar o búfalo (Bubalus bubalis) como um animal de trabalho}

\author{
Cely Vásquez Juan David y Plazas Borrero Camilo Hernando² \\ ${ }^{1} \mathrm{MVZ}$, Universidad de los Llanos y \\ ${ }^{2}$ MVZ, Esp., MSc., Docente Universidad de los Llanos \\ cplazasb@unillanos.edu.co
}

Recibido 03 de Noviembre 2017, Aceptado 26 de Mayo 2018

\section{RESUMEN}

En regiones de Asia y Suramérica, el búfalo (Bubalus bubalis) se ha venido utilizando desde siglos atrás para brindar fuerza de trabajo, en las modalidades de carga, tiro o monta, e incluso en la mecanización de suelos con características de inundación (cultivos de arroz), en donde el lodo puede llegar a una profundidad que alcanza 40 a $60 \mathrm{~cm}$, se pueden desplazar a una velocidad de $6-8 \mathrm{~km} / \mathrm{h}$, y pueden llegar a mover cargas de hasta $1500 \mathrm{~kg}$, con rendimiento de trabajo de 0.25 hectáreas por día. También se observado que la fuerza ejercida por los búfalos como animales de trabajo no representa restricciones al utilizarlos en diferentes labores agropecuarias dentro de las fincas, y su clara adaptación al trópico permite un desarrollo físico adecuado, facilitando su entrenamiento. Se considera como una "tecnología apropiada", el sistema que emplea la combinación de remolque y búfalo, porque sobrepasa la efectividad de la maquinaria en productividad y costos de funcionamiento, lo cual ha generado que, en las plantaciones de palma en el momento de la cosecha, los búfalos sean utilizados como principal fuente de tracción de los remolques que almacenaran este fruto. A pesar de la existencia de zonas ganaderas y productoras de palma africana, en Colombia no se han documentado estudios donde se relacionen los procesos de adiestramiento del búfalo mediante la implementación de doma racional, para utilizarlos como animales de trabajo, por lo cual, el objetivo de este trabajo es exponer las cualidades de esta especie, y las técnicas adecuadas para el 
adiestramiento y manejo de los búfalos destinados para trabajo, con base en su etología y trato racional. Se ha reconocido que los implementos e instalaciones utilizados en el manejo de los búfalos son importantes para facilitar el adiestramiento, los cuales deben ser confortables en caso de la sujeción de la cabeza, en la nariz se utiliza argolla nariguera, también se usan lazos de distintos calibres y un cabezal, pero en ningún caso se debe infringir daño; en actividades de trabajo se utiliza el sillín, la alfombra y el remolque, los cuales no deben limitar la locomoción del búfalo. A diario y durante el ordeño es necesario dedicar de $20 \mathrm{a}$ 30 minutos a la manipulación del bucerro para tener contacto y establecer un vínculo con la persona que lo está entrenando. Para permitir un control y poder guiar al animal, en esta etapa se le enseña algunas órdenes con el lazo pisador y con la voz, halándolo de la cuerda del cabezal atado a la argolla nariguera; los búfalos se deben ejercitar mediante caminatas entre una a dos horas. En el sitio de trabajo se guía al animal, siempre con el amansador por delante para mostrarle los caminos y enseñarle cuales son las calles; este acompañamiento puede variar en cuanto al tiempo de duración, porque con algunos búfalos puede tomar meses y en otros menos, en general se hace el refuerzo de órdenes de voz hasta llevar el animal a trabajar con una sola persona.

Palabras clave: Doma racional, tracción animal, etología, bóvidos, palma.

\section{ABSTRACT}

In regions of Asia and South America, the buffalo (Bubalus bubalis) has been used for centuries to provide workforce, in the modalities of loading, shooting or mounting, and even in the mechanization of soils with flood characteristics (rice crops), where the mud can reach a depth that reaches 40 to $60 \mathrm{~cm}$, they can move at a speed of $6-8 \mathrm{~km} / \mathrm{h}$, and can reach loads of up to $1500 \mathrm{~kg}$, with work performance of 0.25 hectares per day. It was also observed that the force exerted by buffaloes as working animals does not represent restrictions when using them in different agricultural work within the farms, and its clear adaptation to the tropics allows an adequate physical development, facilitating its training. It is considered as an "appropriate technology", the system that uses the trailer and buffalo 
combination, because it exceeds the effectiveness of the machinery in productivity and operating costs, which has generated that, in the palm plantations at the time of harvest, the buffaloes are used as the main source of traction for the trailers that store this fruit. In spite of the existence of cattle and African palm producing areas, in Colombia, no studies have been documented where the training processes of the buffalo are related through the implementation of rational dressage, to use them as work animals, therefore, the objective of this work is to expose the qualities of this species, and the appropriate techniques for the training and management of buffaloes intended for work, based on its ethology and rational treatment. It has been recognized that the implements and installations used in the management of buffaloes are important to facilitate training, which should be comfortable in the case of head restraint, nose ring is used in the nose, also ties of different calibers and a poppet are used, but in no case should harm be inflicted; in work activities the saddle, the carpet and the trailer are used, which should not limit the locomotion of the buffalo. Daily and during milking it is necessary to devote 20 to 30 minutes to the manipulation of the buffalo to have contact and establish a link with the person who is training him. To allow control and to guide the animal, in this stage he is taught some orders with the trapping bow and with the voice, pulling it from the head rope attached to the nose ring; buffaloes should be exercised through walks between one to two hours. At the work site the animal is guided, always with the tamer ahead to show him the roads and show him the streets; this accompaniment may vary in terms of duration, because with some buffaloes it can take months and in others less, in general, voice orders are reinforced until the animal is brought to work with only one person.

Keywords: Rational dressage, animal traction, ethology, bovids, palm.

\section{RESUMO}

Nas regiões da Ásia e da América do Sul, o búfalo (Bubalus bubalis) tem sido usado há séculos para fornecer força de trabalho, nas modalidades de carregamento, tiro ou montagem, e mesmo na mecanização de solos com características de inundação (culturas de arroz), onde a lama pode chegar a uma 
profundidade que atinge 40 a $60 \mathrm{~cm}$, pode mover-se a uma velocidade de 6-8 $\mathrm{km} / \mathrm{h}$, e pode mover cargas de até $1500 \mathrm{~kg}$, com rendimento de trabalho de 0.25 hectares por dia. Também foi observado que a força exercida pelos búfalos como animais de trabalho não representa restrições ao usá-los em diferentes trabalhos agrícolas dentro das fazendas, e sua clara adaptação aos trópicos permite um desenvolvimento físico adequado, facilitando seu treinamento. É considerado como uma "tecnologia apropriada", o sistema que usa a combinação de reboque e búfalo, porque excede a eficácia do maquinária em produtividade e custos operacionais, o cual gerou que nas plantações de palmeiras no momento da colheita, os búfalos são usados como principal fonte de tração para os trailers que armazenam essa fruta. Apesar da existência de áreas de produção de bovinos e palma africana, na Colômbia, nenhum estudo foi documentado onde os processos de treinamento do búfalo estão relacionados através da implementação de dressage racional, para usá-los como animais de trabalho, portanto, o objetivo deste trabalho é expor as qualidades desta espécie, e as técnicas apropriadas para a formação e gestão de búfalos destinados ao trabalho, com base na sua etologia e tratamento racional. Foi reconhecido que os implementos e instalações utilizados na gestão de búfalos são importantes para facilitar o treinamento, que deve ser confortável no caso da sujeição da cabeça, no nariz é usado anel de nariz, também são usados laços de diferentes calibres e uma cabeça, mas em nenhum caso deve causar dano; nas atividades de trabalho a sela o tapete e o reboque são usados, os quais não devem limitar a locomoção do búfalo. Diariamente e durante a ordenha é necessário dedicar 20 a 30 minutos à manipulação do búfalo para ter contato e estabelecer um vínculo com a pessoa que o está treinando. Para permitir o controle e guiar o animal, nesta fase, ele é ensinado algumas ordens com o arco de captura e com a voz, puxando-o da corda da cabeça presa ao anel do nariz; os búfalos devem ser exercitados por uma caminhada de uma a duas horas. No lugar de trabalho, o animal é guiado, sempre com o domador à frente para mostrar-lhe as estradas e ensinar-Ihe quais são as ruas, este acompanhamento pode variar em termos de duração, porque com 
alguns búfalos pode levar meses e em outros menos, em geral, as ordens de voz são reforçadas até que o animal seja levado a trabalhar com apenas uma pessoa.

Palavras-chave: Adestramento racional, tração animal, etologia, bovídeos, palma.

\section{INTRODUCCIÓN}

Los animales de trabajo ayudan en la subsistencia a los pequeños agricultores, quienes los utilizan para la labranza del suelo, lo cual aumenta la cobertura de preparación del suelo en menor tiempo, es decir que contribuye eficientemente con su trabajo de campo; también los pueden utilizar en el transporte de cosechas, facilitando la comercialización de sus productos, en suministro de forraje para el ganado, y transporte de estiércol e insumos que se requieren en la finca, suministrando a las familias servicios y medios de vida. El poder humano, animal y mecánico no es mutuamente excluyente y cada uno tiene ventajas dependiendo del ambiente, la escala y el contexto socioeconómico. La gente aspira a máquinas prestigiosas y modernas, pero los tractores pueden ser inasequibles e inapropiados en pequeñas explotaciones o en terrenos difíciles (Borghese y Mazzi, 2005).

El bienestar de los animales se reconoce como un componente básico en la cría responsable y por lo tanto debe ser una parte integral de todos los sistemas de producción, además de ser un bien común, tiene un impacto directo en salud de los animales y en su capacidad para llevar a cabo las funciones requeridas, que a su vez afectan el sustento de sus propietarios. Sin embargo, las prácticas de bienestar no reciben suficiente atención en todo el mundo a pesar de sus reconocidos impactos positivos en los animales y las familias que los poseen (Borghese y Mazzi, 2005).

\section{DESCRIPCIÓN E IMPORTANCIA DEL BÚFALO EN ACTIVIDADES ZOOTÉCNICAS}

Del búfalo doméstico de agua o asiático Bubalus bubalis se derivan dos tipos de sub-especies: Bubalus bubalis bubalis (búfalo de rio) y Bubalus bubalis karabau 
(búfalos de pantano), pertenecen al orden Artiodactyla y al sub orden rumiantes (Zava, 2011). La clasificación para estas dos sub-especies se basa en las características anatómicas, fisiológicas y adaptativas, y su ubicación geográfica.

El búfalo de agua (Bubalus bubalis) se ha convertido en una especie con alto interés zootécnico a nivel mundial. En Colombia su potencial como animal triple propósito es altamente reconocido, sin embargo, el sector en el cual se desarrolla como una valiosa opción de negocio es la industria láctea, especialmente para la producción de quesos tipo Mozzarella; mientras que la producción cárnica y de animales para trabajo está en crecimiento, debido al interés de ganaderos y propietarios de plantaciones de palma africana. Se caracteriza como un animal gregario, dócil, inteligente y con un temperamento tranquilo, posee hábitos nocturnos, es semiacuático, rustico, longevo, alta resistencia a enfermedades, habilidad para adaptarse a variaciones de temperaturas y consumo de alimentos toscos (Torres, 2009; ASOBUFALOS, 2016).

El búfalo se ha venido utilizando desde siglos atrás en antiguas culturas en regiones de Asia y sur América para brindar fuerza de trabajo, en las modalidades de carga, tiro o monta; ha trabajado en la mecanización de suelos con características de inundación (cultivos de arroz), en donde el lodo puede llegar a una profundidad de hasta 40 a $60 \mathrm{~cm}$, dificultado las labores con otro tipo de equipos, siendo los animales la mejor opción debido a su agilidad de desplazamiento y características anatómicas como: pezuña hendida, alzada tipo medio, caja torácica profunda, extremidades cortas y articulaciones flexibles, los hace muy estables en la locomoción por su bajo centro de gravedad; inclusive logrando por medio del pisoteo labores de descompactación y control de arvenses. Se caracteriza por su comportamiento dócil y gran capacidad de fuerza, logrando tirar cargas de hasta el doble de su peso vivo (velocidad de trabajo es de 6-8 $\mathrm{km} / \mathrm{h}$, y pueden llegar a mover cargas de hasta $1500 \mathrm{Kg}$ ) con rendimiento de trabajo de 0.25 hectáreas por día (Zava, 2011).

El objetivo de este artículo es explicar el proceso de "doma racional" que hace referencia de como amansar un animal usando la razón para desarrollar 
apropiadamente sus capacidades para que sea más eficiente fundamentalmente como animal de trabajo, lo cual va de la mano con el conocimiento etológico de la especie en este caso los búfalos. Lo racional y la etología se enfocan en el bienestar animal, estado físico (sanos) y mental (nobles y obedientes), brindando un proceso de amanse sin que se presenten traumas, estereotipias y/o agresiones hacia sus manejadores (Prado, 2009).

Se pretende exponer las cualidades de esta especie y las técnicas adecuadas para el amanse y manejo de los búfalos destinados para trabajo, con base en su etología y trato racional, buscando la aceptación por parte del animal hacia el hombre, utilizando los implementos adecuados para facilitar este proceso de adiestramiento, los cuales deben ser confortables para permitir desarrollar su fuerza y capacidad de trabajo.

\section{IMPLEMENTOS DE SUJECIÓN, TRACCIÓN Y TRABAJO}

Para permitir la guía y sujeción de la cabeza y nariz, sin infringir daño alguno, se utiliza la argolla nariguera, lasos de distintos calibres y un cabezal (Figura 1).

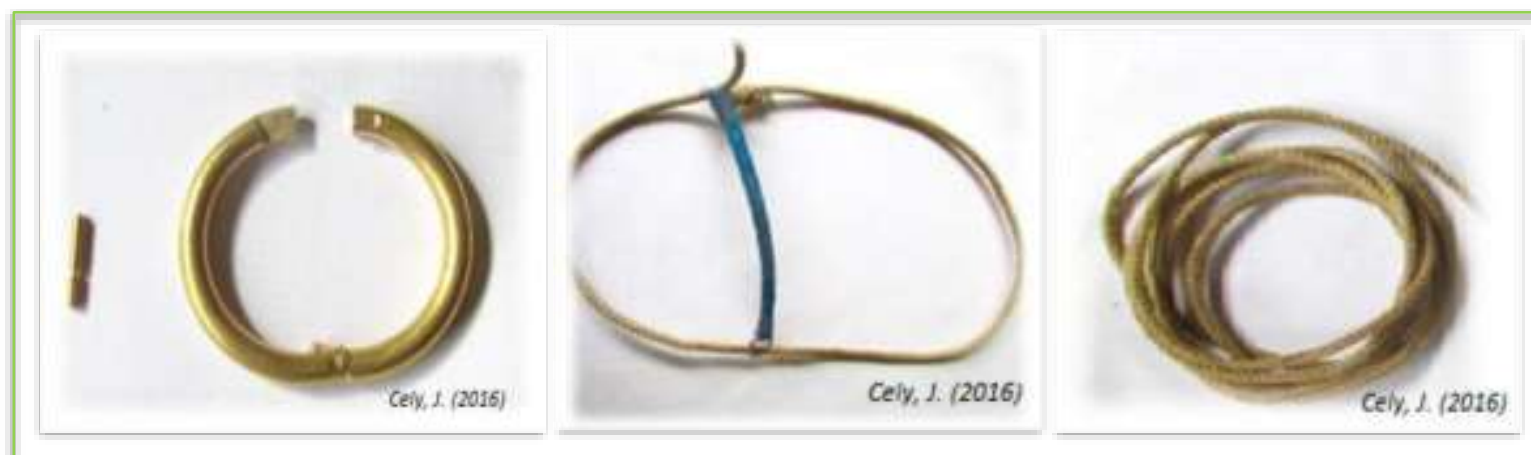

Figura 1. Implementos para el manejo de los búfalos.

Para ejecutar las labores de trabajo se utiliza el sillín, la alfombra y el remolque, implementos sobre los cuales el animal sostiene la carga; para no limitar la locomoción del búfalo durante la marcha se usa un juego de cuatro correas, las cuales deben ser colocadas correctamente para sujetar los equipos de trabajo. Estos implementos se caracterizan por su gran resistencia y permitir la correcta movilidad de los animales (Figura 2). 


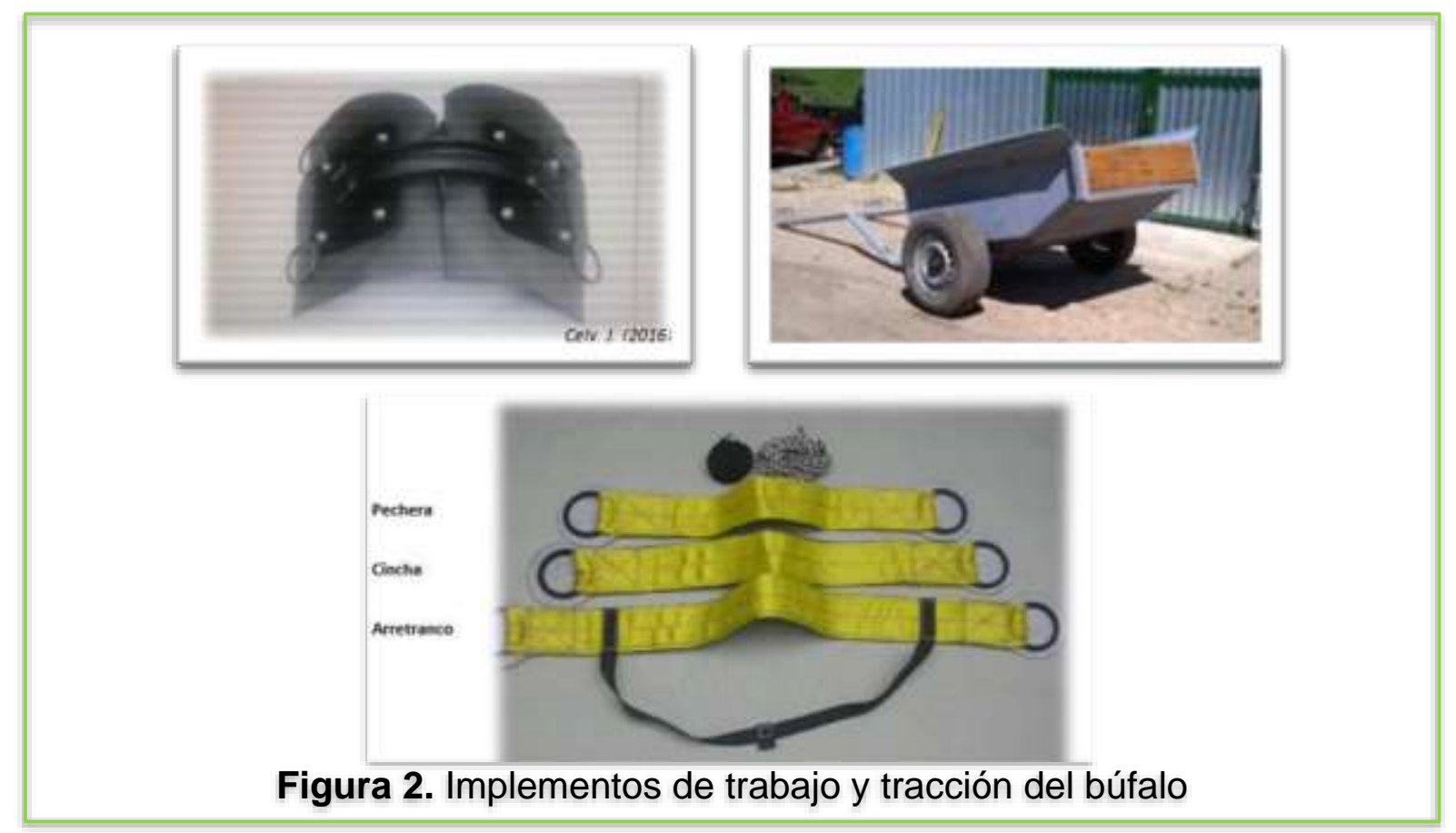

\section{INSTALACIONES}

Es imprescindible que se respeten los postulados de la Buenas Prácticas Ganaderas (BPG), para brindar bienestar y confort a los animales en el proceso de doma racional. El corral debe ser amplio, preferiblemente en tierra para evitar que los animales resbalen; poseer una buena calceta de ancho $80 \mathrm{~cm}$ permitiendo el paso de los búfalos sin dificultad; lugares de equipamiento y de acostumbramiento amplios, de fácil visibilidad, con buena sombra y que no tengan obstáculos en su alrededor (Botero y de la Ossa, 2003) (Figura 3).

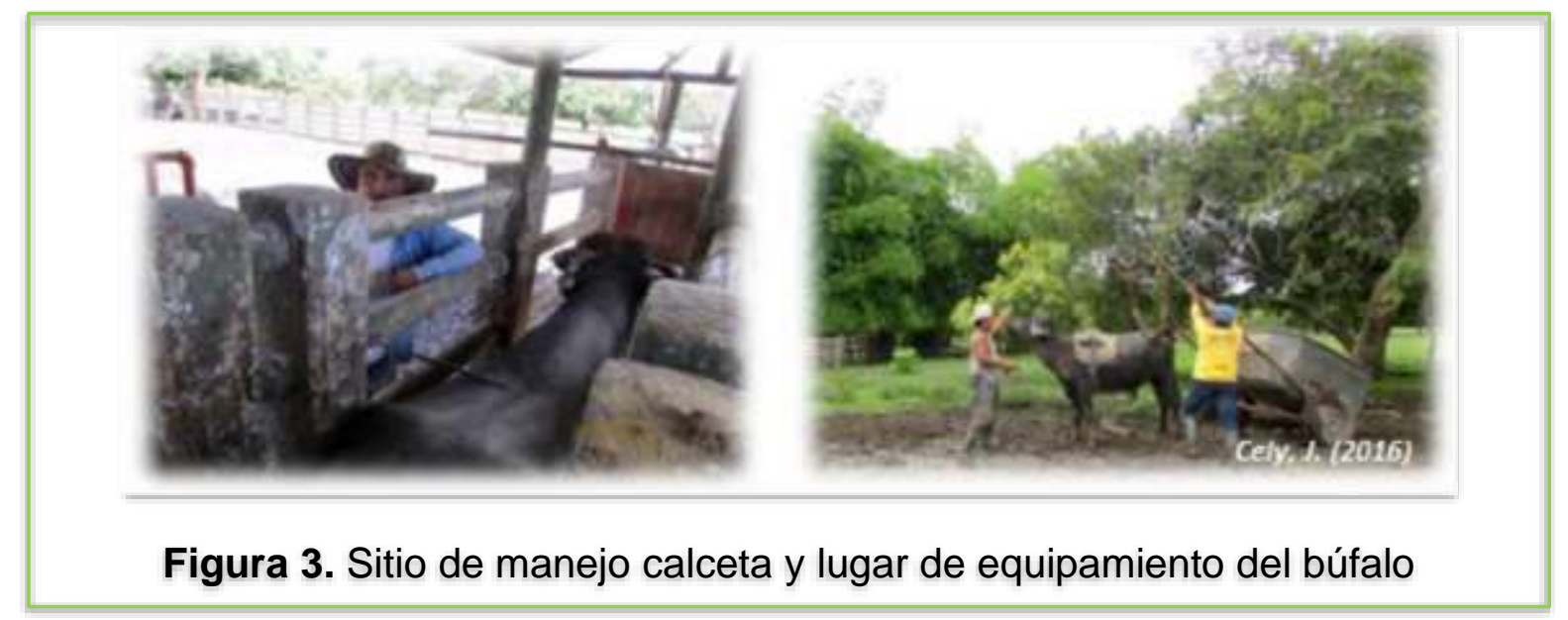




\section{FACTORES QUE INFLUYEN EN DOMA RACIONAL}

Cuando el búfalo vive en la naturaleza es presa de depredadores, presenta un comportamiento característico, se encuentra en alerta a movimientos bruscos, ruidos y puede detectar las actitudes de las personas que se acerquen a él, presentando respuestas grupales. Lo anterior, hace recurrir a un método denominado "imprinting" o impronta, que se refiere a una forma de aprendizaje temprano en el qué un recién nacido fija su atención en el primer ser vivo que huele, observa, escucha o toca, que es la madre, por lo tanto el proceso de amanse inicia en las primeras horas del nacimiento, en el momento de la curación del ombligo, seguido de los ocho meses de lactancia (Figura 4).

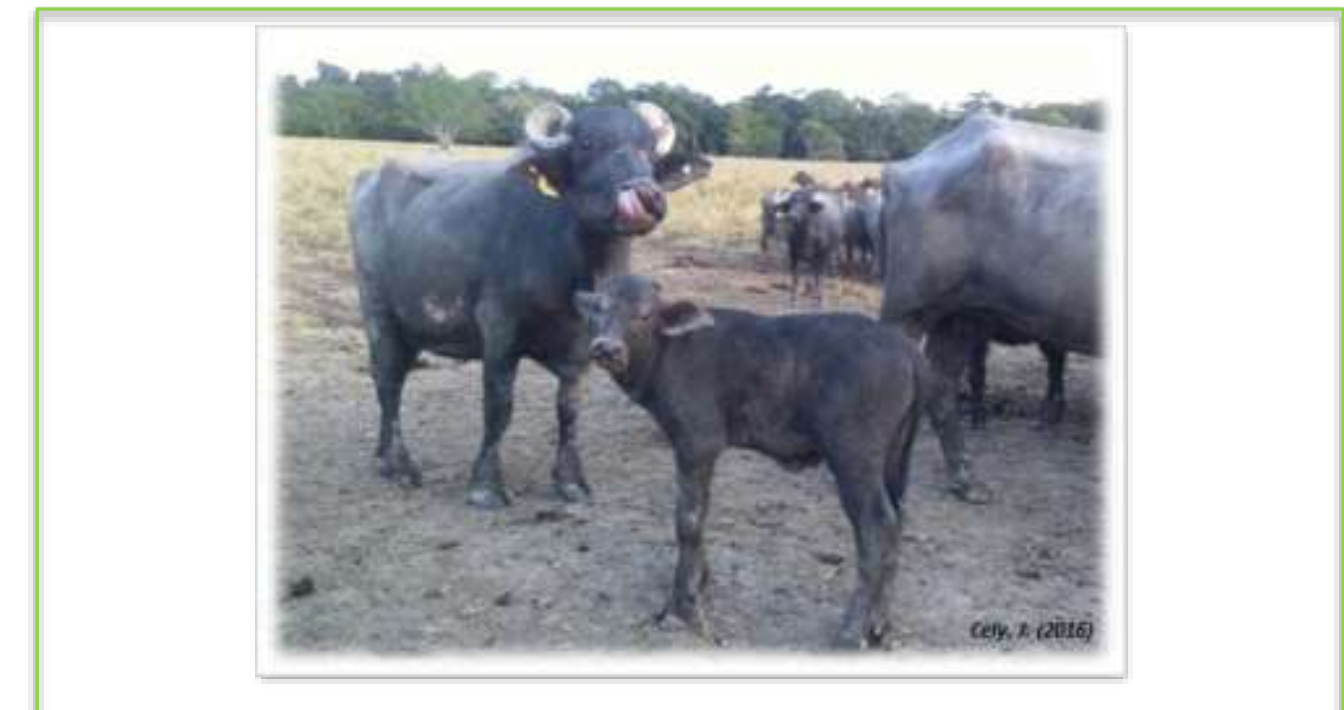

Figura 4. Búfalas con crías que empezaron el proceso de amanse

A diario y durante el ordeño es necesario dedicar de 20 a 30 minutos a la manipulación del bucerro: dejándose olfatear, se acaricia todo su cuerpo, se rasca su frente, debajo de la cola y entre las patas, puntos del cuerpo que al estimularlos producen relajación; igualmente se debe repetir en las horas de la tarde durante las labores de manejo, reforzando la confianza de los bucerros con las personas. 
Es necesario crear una línea cronológica del ejercicio, en la cual se identifican los distintos tiempos del adiestramiento, permitiendo de esta manera encontrar puntos claves, y así mejorar los procedimientos. Durante el proceso de ordeño se establece una familiaridad de los bucerros (bufálo lactante) con las personas que los manejan; cuando tienen 24 a 36 meses, se debe tener en cuenta distintos parámetros que facilitan determinar sí los animales tienen la capacidad para ser destinados al trabajo y por tanto se continua con el proceso de doma.

Las características físicas y clínicas apropiadas del búfalo para trabajo son: extremidades anteriores y posteriores rectas, patas cortas, huesos desarrollados, articulaciones bien conformadas y sin lesiones ni cojeras, cascos grandes y pezuñas de igual tamaño; cabeza ancha con pestañas fuertes y abundantes, ojos brillantes y vivaces, cuernos fuertes, bien definidos, sin fracturas que faciliten la movilidad, dentadura sana, morro amplio, fuerte, humedecido y brillante; cuello corto, fuerte y musculoso; línea dorsal recta desde la cruz hasta la altura del sacro, pecho ancho y profundo; abdomen que no sea abultado y barril profundo, sin presencia de hernias; cola flexible, con gran movilidad y bien implantada. El peso de un búfalo adulto para realizar cualquier trabajo debe estar entre 400 y $450 \mathrm{Kg}$, con buen desarrollo corporal (Galindo, 1998; Almaguer, 2007).

\section{CARACTERÍSTICAS COMPORTAMENTALES}

Es indispensable que a través de la observación se detecten las características comportamentales y que la selección del búfalo adecuado para trabajo, la realicen personas que tengan los conocimientos y la experiencia; el comportamiento se expresa cuando interactúa con el hombre, el ambiente y otros animales en el desarrollo de la actividad para la cual se destinó, siendo éstas un reflejo de su personalidad y actitud. Además, es necesario tener en cuenta las conductas innatas y la habilidad posterior de expresar las adquiridas, con el fin de lograr una actitud correcta para un manejo eficiente, tales como: alto grado de docilidad e inteligencia, fácil adaptabilidad al hombre y al trabajo, demostrar disposición y obediencia, poseer un comportamiento calmado, ser curioso, sensitivo y con un 
nivel alto de mansedumbre, y que exprese su fuerza, brío, vitalidad y rusticidad (Galindo, 1998; Almaguer, 2007; Torres, 2009).

\section{ASOCIACIÓN BÚFALO-HOMBRE}

Se deben implementar técnicas racionales con los animales adultos mediante ejercicios que conlleven a una aceptación de proximidad y contacto físico, generando vínculos de confianza con los operarios y tranquilidad en los animales. Con el uso de una vara de madera y en espacios reducidos dentro del corral, con grupos de 5 a 10 animales, se inicia un toque y rascado con el fin de acostúmbralos al contacto físico; estos movimientos deben ser lentos, sin sobresaltos y al hablarles se debe hacer de forma pausada. Una vez se identifique el búfalo que más corresponda, se utiliza como apoyo para un acercamiento con los demás animales. Este proceso requiere de un tiempo considerable, por lo menos de dos horas diarias, por varios días y en condiciones ambientales favorables para evitar el estrés (Figura 5).

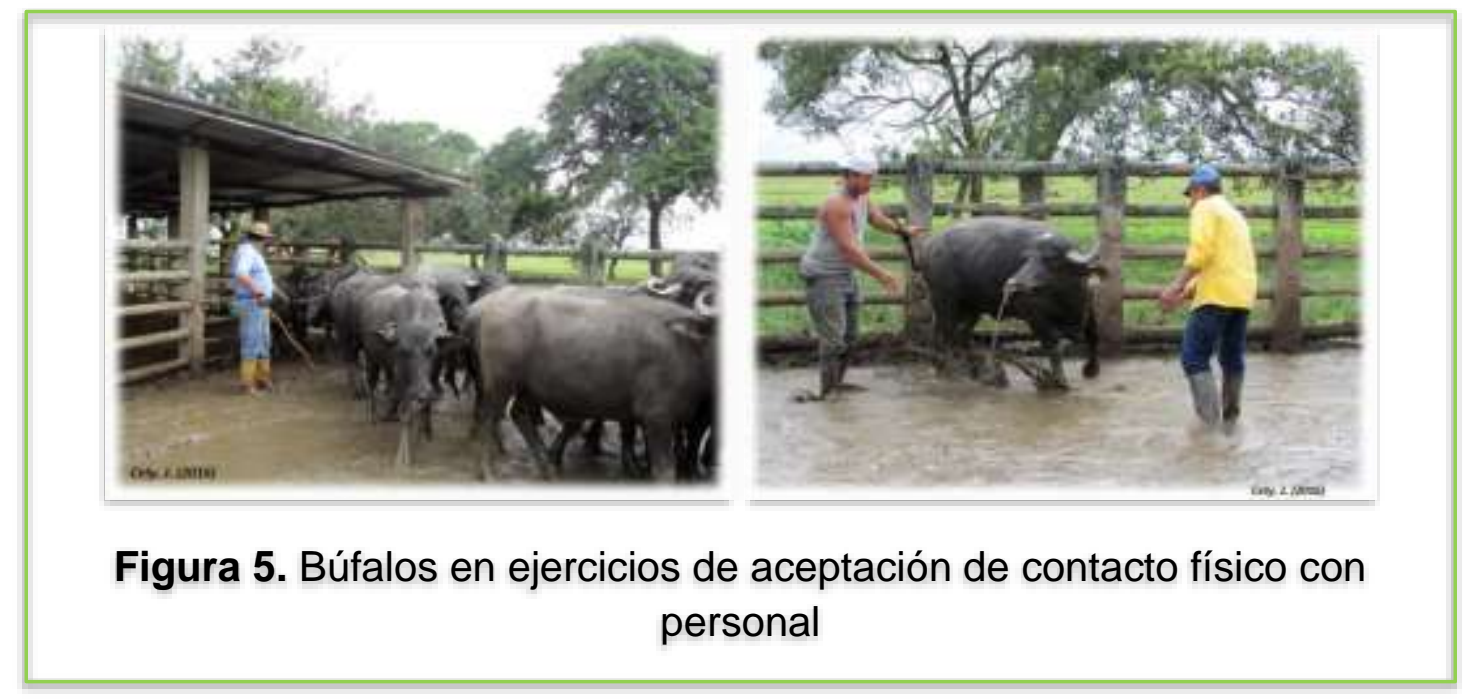

Para el argollado se debe hacer uso de la manga del corral con el fin de evitar traumatismos, dolor, estrés físico y rechazo hacia las personas, en lo posible con uso de tranquilizantes y/o anestésicos locales (bloqueo del nervio facial a través del agujero infraorbitario) (Cely y Puerto, 2016). Para la perforación se debe palpar 
con la punta de los dedos el lugar por donde debe pasar el punzón de acero inoxidable, es necesario estirar la nariz para poder tocar y perforar solo el pliegue sin dañar el cartílago, luego se retira el punzón e inmediatamente se coloca la argolla, asegurándola con el tornillo pasador, revisando que quede centrado para evitar su pérdida; posteriormente se coloca dentro de la argolla un lazo calibre 8 de $80 \mathrm{~cm}$ de largo, el cual servirá para sujetar el animal para el acostumbramiento, y se debe evitar que el búfalo pise el lazo y con ello se maltrate la nariz. Una vez sane la herida (15 días) se continua con el adiestramiento (Figura 6).

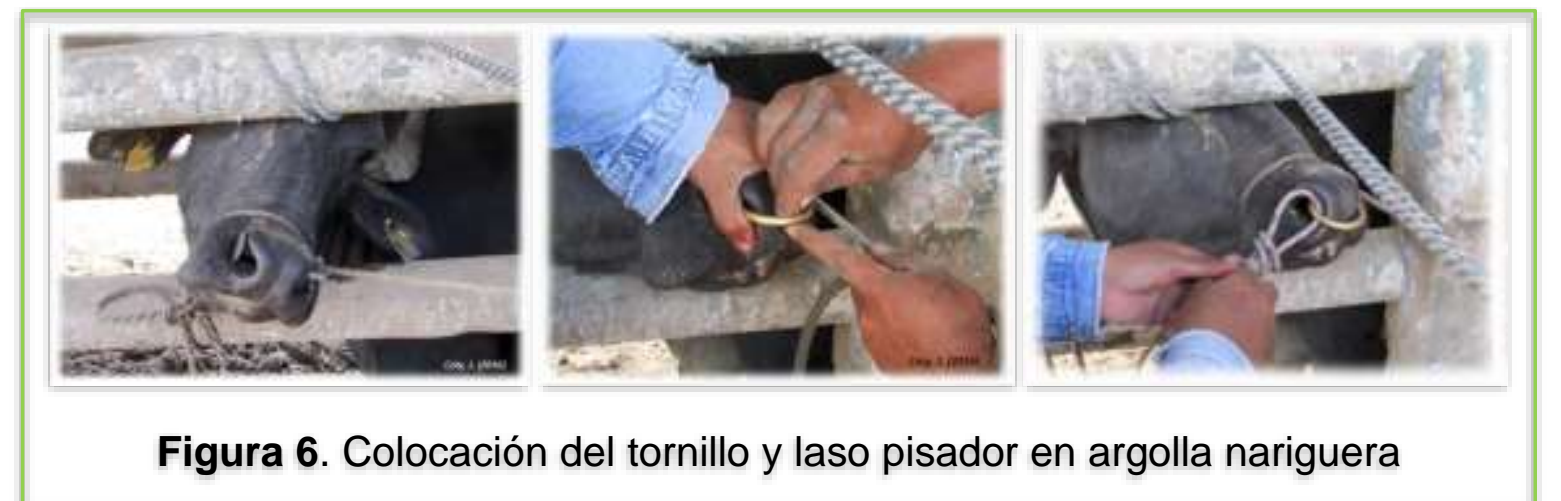

El proceso de descosquillado se realiza en la calceta, donde al animal se le coloca el cabezal, el cual se ata al lazo de la argolla, de tal forma que se reparta la fuerza una vez se amarre a un costado de la calceta, entonces se inicia el ejercicio de tocarlo de manera sistemática y en orden desde su anca hacia adelante. En el caso de que haya avances en el ejercicio y acceda dócilmente, se le estimulara aflojando la nariz, en caso contrario, deberá ejercerse fuerza nuevamente (Hoyos y Adelaida, 2016). Este primer ejercicio debe ir acompañado de cepillado constante por todo el cuerpo y de palabras como "quieto", "tranquilo" así como un nombre, que se le repite constantemente, con el cual él termina relacionándose (Figura 7).

Los búfalos se amarran en el corral a la sombra para que constantemente se toquen y rasquen cuidadosamente con escoba o cepillo, es importante recordar algunos puntos de relajación de los búfalos como son, debajo de la cola en la 
entrepierna y detrás de las orejas. Por otra parte, se puede también utilizar baños, con una manguera o baldes, esto ayuda a que el animal se sienta confortable. Los ejercicios de descosquilleo se deben realizar a diario, entre una a dos horas, y los animales deben quedar en el sitio de acostumbramiento por espacio de ocho horas, luego se sueltan tranquilamente, evitando que se asusten para no provocar desconfianza (Figura 7).

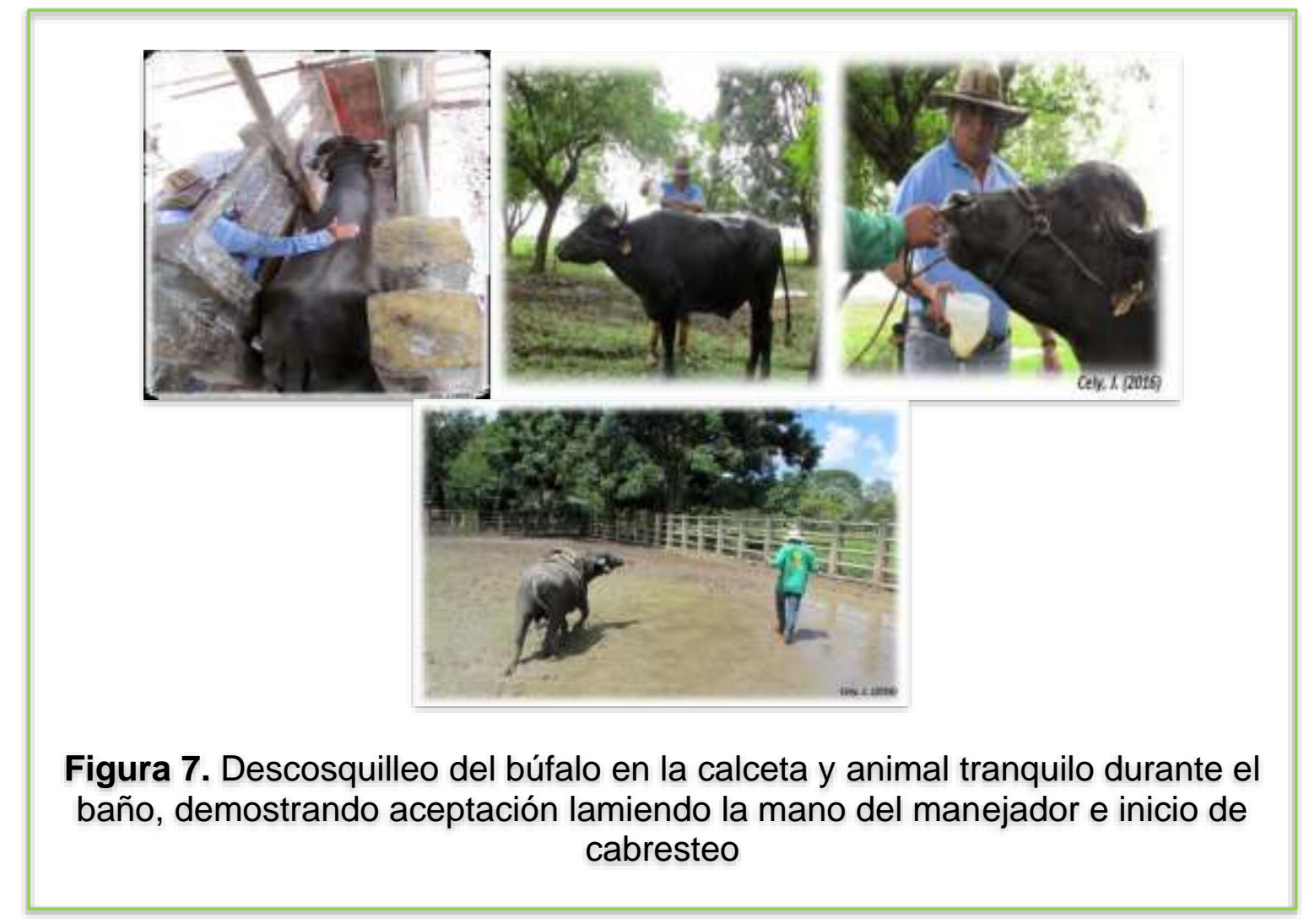

\section{CABRESTEO}

En esta etapa, para permitir un control y poder guiar al animal, se le enseña algunas órdenes con el lazo pisador y con la voz, halándolo de la cuerda del cabezal atado a la argolla nariguera. La persona que realiza la actividad se debe colocar a un costado del búfalo y sobrepasarlo a nivel de la cruz para que avance; para dar la orden de detenerse se da unos pasos delante de la cruz y se le dice "alto" o "quieto" sosteniendo el lazo levantando la cabeza. Parte del cabresteo es hacer caminatas entre una a dos horas. En un corral grande se practican constantemente todos los ejercicios descritos anteriormente (Figura 7). 


\section{COLOCACIÓN DE IMPLEMENTOS AL BÚFALO}

En esta etapa del amanse se hace la presentación de los implementos, con el objetivo de que el búfalo los conozca los huela y no le parezcan extraños, se le muestran de cerca las correas, lazos y sillín, permitiendo que los vea y se familiarice con ellos, seguido se procede a colocarlos; junto con esta actividad, se refuerza diariamente la aceptación del contacto del búfalo con las personas, cuando el animal es equipado con el sillín, se le quita y se le pone repetidas veces, y se aprieta la cincha para llevarlo a caminar de cabestro. La alfombra se le puede pasar por todo el cuerpo antes de colocarla en el lomo para reforzar el descosquilleo, luego se ubica el sillín, y después las correas, empezando a cinchar el sillín, después la pechera, y por último se sitúa el arretranco; se deben revisar las correas que estén bien ajustadas para que no lastimen al animal, luego se lleva a caminar, una vez terminado el ejercicio se retiran los implementos y se baña el animal para su descanso.

La presentación del remolque al animal, se hace acercándolo con cuidado para que genere confianza, hasta lograr su tranquilidad con el implemento cerca, cuando lo acepte se procede a colocarlo atando bien las correas, para ello, el búfalo se ubica frente al remolque y con ayuda de dos personas se coloca suavemente el remolque sobre el búfalo; lo primero que se asegura es la pechera, seguida de la cincha y por último el arretranco, se deben revisar todos los lazos y hacer nudos seguros pero que sean fáciles de soltar, luego se lleva a ejercitar para acostumbrarlo a este implemento (Figura 8).

Para el reconocimiento del trabajo en la granja, el animal debe ser trasladado al predio donde va a ser utilizado como fuerza de trabajo, y se inicia con un proceso de acostumbramiento, porque el cambio de lugar al animal le genera intranquilidad; se debe tratar como la primer vez que se ensilló, presentándole a las personas que van a trabajar con él, siendo similar al proceso que se realizó en las primeras etapas del amanse. En el lugar de trabajo se guía al animal, siempre con el amansador por delante para mostrarle los caminos y enseñarle en el caso de los cultivos de palma, cuáles son las calles de cosecha y las de basura, puesto 
que el búfalo se movilizara siempre por las calles designadas como de cosecha, este acompañamiento puede variar en cuanto al tiempo de duración, con algunos búfalos puede durar meses y en otros tardar solo una o dos semanas; al mismo tiempo se hace todo el refuerzo de órdenes de voz hasta llevar el animal a trabajar con una sola persona que se desplazara detrás del búfalo.

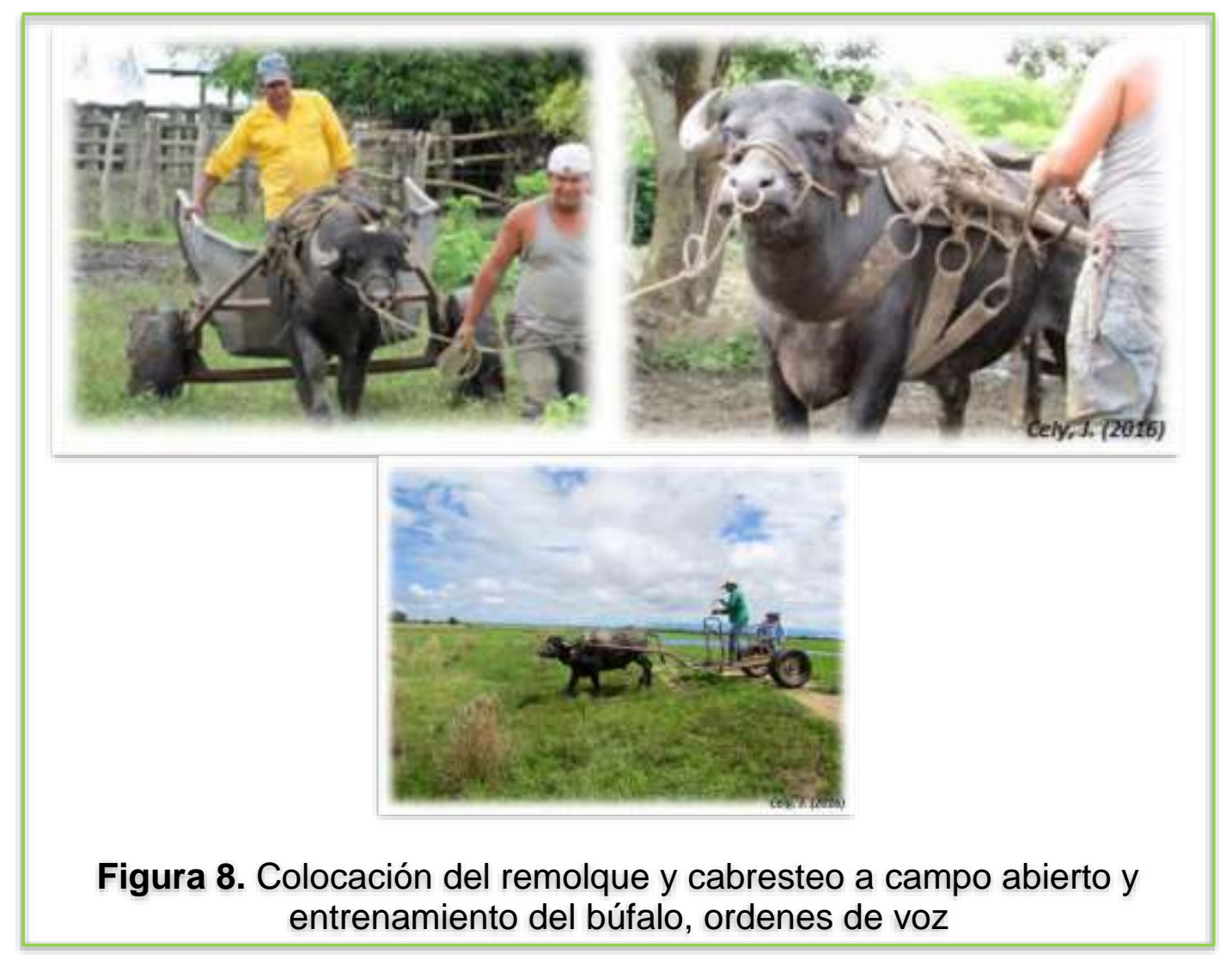

\section{CONCLUSIONES}

Se ha reconocido que los implementos e instalaciones utilizadas en el manejo de los búfalos son importantes para facilitar el amanse y adiestramiento, los cuales deben, ser confortables en caso de la sujeción tracción y actividades de trabajo.

Es importante empezar la doma del búfalo que se va a destinar para trabajo desde cuando nace, y durante el ordeño es necesario dedicar de 20 a 30 minutos a la manipulación del bucerro para tener contacto conocimiento de la persona que lo está entrenando, ejercitándolos mediante caminatas de una a dos horas al día. 
Son importantes las técnicas racionales con los animales adultos, implementadas mediante ejercicios que conllevan a una aceptación de la proximidad y contacto físico, generando vínculos de confianza con los operarios y tranquilidad en los animales. Con el uso de una vara de madera y en espacios reducidos dentro del corral, con grupos de 5 a 10 animales, se inicia un toque y rascado con el fin de acostúmbralos al contacto físico.

\section{REFERENCIAS BIBLIOGRÁFICAS}

1. Almaguer Y. El búfalo, una opción de la ganadería, REDVET. Revista electrónica de Veterinaria, 8 (8): 1-23. 2007. Recuperado 18 Julio 2017. Disponible En: http://www.veterinaria.org/revistas/redvet/n080807/080709.pdf

2. ASOBUfALOS, Asociación Colombiana de Criadores de Búfalos. 100 preguntas sobre los búfalos. Editorial Asobúfalos, Medellín, Colombia. 82 p. 2016.

3. Borghese A., Mazzi M., Buffalo population and strategies in the world. Buffalo production and research. Reu Technical Series 67. Consiglio per la ricerca e la sperimentazione in agricoltura (CRA), Istituto Sperimentale Per La Zootecnia (ISZ) y Organización de las Naciones Unidas para la Alimentación y Agricultura (FAO), Roma, Italia. 316 p. 2005.

4. Botero L.M., de la Ossa J., Guía para la cría, manejo y aprovechamiento sostenible de algunas especies animales: mamíferos herbívoros domésticos. Convenio Andrés Bello, Bogotá, Colombia. 76 p. 2003.

5. Cely J., Puerto A. Implementación de técnicas de doma racional en el proceso de amanse y adiestramiento del búfalo para trabajo en Hacienda Bélgica, Maní, Casanare. En: XI Congreso Mundial de Búfalos. 127 p. 2016.

6. CRMV-MG, Conselho Regional de Medicina Veterinária do Estado de Minas Gerais. Doma racional de bovinos. Cadernos Técnicos de Veterinára e Zootecnica N. 78. Universidad Federal de Minas Gerais, Belo Horizonte, Brasil. 90 p. 2015.

7. Galindo W. El amansamiento y adiestramiento de búfalos para trabajo. Fundación Centro para la Investigación en Sistemas Sostenibles de Producción Agropecuaria (Cipav), Cali, Colombia. 21 p. 1998.

8. Hamid S.K., Farooq M., Mian M.A., Syed M., Jamal S. Milk production performance and inter-relationsship among traits of economic importance in buffaloes maintained at commercial dairy farms, Livestock Research for Rural Development, 15 (10), 2003. Recuperado 20 Julio 2017. Disponible En: http://www.Irrd.org//lrd15/10/hami1510.htm

9. Hoyos J.F., Adelaida R. Caracterización de las tendencias en la doma de caballos silla colombiano. Facultad de Ciencias Agropecuarias. 8 (1): 3-11. 2016.

10. López I., Alonso I., Fajardo V., Rodríguez M., Hernández P., García T., Martín R. PCR detection of cows' milk in water buffalo milk and mozzarella cheese. International Dairy Journal. 15 (11): 1122-1129. 2005. 
11. Montiel N. El Búfalo: Otra alternativa de producción de leche, Ergomix, 2009. Recuperado 18 Julio $2017 . \quad$ Disponible En: https://www.engormix.com/ganaderia-leche/articulos/bufalo-otra-alternativaproduccion-t28045.htm

12. Patiño E.M., Crudeli G.A., Valdés A.M. Bubalinocultura de las Américas. Moglia Ediciones, Argentina. 273 p. 2011.

13. Prado J.M. Doma racional sin violencia en equinos, Ing de Ejecución Agropecuaria. Facultad de Ciencias. Escuela de Ciencias y Tecnología en Recursos Agrícolas y Acuícolas, Universidad de Magallanes, Chile. 47 p. 2009.

14. Rosales R. Situación del búfalo de agua en Costa Rica. Revista Tecnología en Marcha. 24 (5): 19-24. 2011.

15. Rosales R., WingChing R. Sistemas de producción bufalinos en Costa Rica. I. Cuantificación de la población y caracterización de los sistemas. Agronomía Costarricense. 31 (2): 65-69. 2007.

16. Ruiz J.D. Producción bufalina en Colombia: del trópico para el mundo. CES Medicina Veterinaria y Zootecnia. 11 (2): 1. 2016.

17. Torres E. Búfalos: Una Especie Promisoria, Sitio Argentino de Producción Animal, 1-5. 2009. Recuperado 16 Julio 2017. Disponible En: http://www.produccionanimal.com.ar/informacion tecnica/razas de bufalos/69-Bufalos peru.pdf

18.Zava M. El búfalo doméstico. Ed. Orientación grafica. OGE-INTA, Argentina. 900 p. 2011. 